\title{
Association of Metabolic Syndrome with the Adiponectin to Homeostasis Model Assessment of Insulin Resistance Ratio
}

\author{
Yu-Song Ding, ${ }^{1,2}$ Shu-Xia Guo, ${ }^{2,3}$ Ru-Lin Ma, ${ }^{2}$ Shu-Gang Li, ${ }^{2}$ Heng Guo, ${ }^{2}$ Jing-Yu Zhang, ${ }^{2}$ \\ Mei Zhang, ${ }^{2}$ Jia-Ming Liu, ${ }^{2}$ Jia He, ${ }^{2}$ Yi-zhong Yan, ${ }^{2}$ Wen-Jie Zhang, and Lie-Gang Liu ${ }^{1}$ \\ ${ }^{1}$ Department of Nutrition and Food Hygiene, Tongji Medical College, Huazhong University of Science and Technology, \\ Wuhan 430030, China \\ ${ }^{2}$ Department of Public Health, Shihezi University School of Medicine, Shihezi, Xinjiang 832000, China \\ ${ }^{3}$ Department of Pathology and Key Laboratory of Xinjiang Endemic and Ethnic Diseases (Ministry of Education), \\ Shihezi University School of Medicine, Shihezi, Xinjiang 832002, China
}

Correspondence should be addressed to Lie-Gang Liu; liegangliu123@163.com

Received 24 July 2015; Accepted 20 September 2015

Academic Editor: Consolato M. Sergi

Copyright (C) 2015 Yu-Song Ding et al. This is an open access article distributed under the Creative Commons Attribution License, which permits unrestricted use, distribution, and reproduction in any medium, provided the original work is properly cited.

\begin{abstract}
This study aimed at determining whether the adiponectin to HOMA-IR (A/H) ratio is associated with MetS and MetS components and comparing the diagnostic efficacy of adiponectin, HOMA-IR, and the A/H ratio in healthy, middle-aged participants. MetS was assessed in 1628 Kazakh participants (men, 768; women, 860). The associations between adiponectin, HOMA-IR, and the A/H ratio with the components of MetS and MetS were examined using logistic regression analysis and receiver operating characteristic (ROC) curves. Our results show that $\mathrm{A} / \mathrm{H}$ ratio may be a better diagnostic marker for MetS than either HOMA-IR or adiponectin alone, and it may serve as an important biomarker to determine an increased risk for MetS in healthy middle-aged population.
\end{abstract}

\section{Introduction}

Metabolic syndrome (MetS) refers to several interrelated cardiometabolic risk factors including dysglycemia, obesity (particularly central adiposity), elevated blood pressure, elevated triglyceride (TG) levels, and low high-density lipoprotein cholesterol (HDL-C) levels $[1,2]$. The prevalence of MetS is approximately $25 \%$ in adults, and it is increasing $[3,4]$. MetS and its components are associated with an increased risk of type 2 diabetes and cardiovascular disease [5, 6]. The risks of heart disease, stroke, and diabetes are increased 1.5- to 3fold in people with MetS compared with people without MetS [7]. As a result, MetS is now both public health and clinical problem [8]. Therefore, to decrease the incidence, there is a need to establish a suitable and sensitive screening marker to identify individuals at high risk for MetS.

The accumulated evidence indicates that insulin resistance (IR) with compensatory hyperinsulinemia is an important pathogenic factor for MetS $[9,10]$, although a precise mechanism linking a specific MetS component with IR is lacking $[11,12]$. In epidemiological studies, the homeostasis model assessment-insulin resistance (HOMA-IR) acts as an important index of IR $[13,14]$.

Adiponectin, which is the most abundant circulating adipokine, is recognized as a critical regulator of insulin sensitivity $[15,16]$, tissue inflammation $[17,18]$, and lipid metabolism $[19,20]$. Furthermore, a growing body of evidence suggests that decreased serum adiponectin is associated with most of the MetS components and therefore MetS $[21,22]$.

Hyperinsulinemia might have a negative impact on circulating adiponectin levels, thereby causing IR. HOMA-IR and adiponectin are thought to represent two different and opposite aspects of IR. The adiponectin concentration to HOMA-IR ratio (A/H ratio) is expected to be more sensitive than either parameter alone for the evaluation of MetS risk.

The $\mathrm{A} / \mathrm{H}$ ratio as an index of MetS was first proposed in 2011 [23]. However, this study included an aged Japanese sample, and the analysis included markers that were measured only once. The association between the $\mathrm{A} / \mathrm{H}$ ratio and MetS is yet to be confirmed, owing to limited evidence. Therefore, studies are needed to determine if there is a relationship 
between the $\mathrm{A} / \mathrm{H}$ ratio and MetS and if this relationship is stronger than the individual parameters. This study aimed at determining whether the $\mathrm{A} / \mathrm{H}$ ratio is associated with MetS and comparing the strength of the associations between MetS and adiponectin, HOMA-IR, and the $\mathrm{A} / \mathrm{H}$ ratio.

\section{Materials and Methods}

2.1. Ethics Statement. The Institutional Ethics Review Board (IERB) at the First Affiliated Hospital of Shihezi University School of Medicine approved the study (IERB number SHZ2009LL05). Standard university hospital guidelines including informed consent, voluntary participation, confidentiality, and anonymity were followed. All participants provided written informed consent before participation.

2.2. Settings and Participants. The survey was conducted from 2009 to 2013 in Xinyuan County, Xinjiang, which is located approximately 4,400 km (2,739 miles) from Beijing; approximately $98 \%$ of the population is Kazakhs. Multistage (prefecture-county-township-village) stratified cluster random sampling was used to select the participants. At the beginning of the study, we chose the Yili prefecture based on the geographical distributions of the minority populations in Xinjiang. We randomly selected one county in Yili prefecture and one township from each county (Nalati Township in Xinyuan County). During the last stage, a stratified sampling method was used to select corresponding villages in each township (3 villages in Nalati Township). We interviewed local Kazakhs aged $\geq 18$ years who had resided in the village for at least 6 months. We successfully interviewed a total of 1628 individuals (860 women and 768 men). Exclusion criteria included acute illness within the previous 2 weeks, currently taking medication, cancer, and pregnancy. The overall response rate was $87.0 \%$.

2.3. Anthropometric Measurements and Laboratory Tests. Each participant was interviewed using a structured questionnaire to collect general and demographic information (age and sex) as well as cigarette smoking history (never smoked, ex-smoker, or current smoker). Waist circumference (cm) was measured midway between the lower rib and iliac crest. Weight $(\mathrm{kg})$ and height $(\mathrm{m})$ were measured with the participants in light clothing. Body mass index (BMI) was calculated as weight $(\mathrm{kg})$ divided by the square of height $\left(\mathrm{m}^{2}\right)$ and expressed as $\mathrm{kg} / \mathrm{m}^{2}$. Casual blood pressure (BP) was measured 3 times after a $5 \mathrm{~min}$ rest in the sitting position using a mercury sphygmomanometer, and an average of 3 measurements was used for analyses. After the physical examination, a blood sample was drawn from the cubital vein in the morning after an overnight fast and was placed in tubes containing heparin sodium. The blood was centrifuged at $2000 \mathrm{rpm}$ for $10 \mathrm{~min}$, and plasma was then separated and stored at $-70^{\circ} \mathrm{C}$ until analysis. Total cholesterol (TC), TG, low-density lipoprotein cholesterol (LDL-C), HDL-C, and fasting blood glucose (FBG) levels were measured using a biochemical autoanalyzer (Olympus AU 2700; Olympus Diagnostics, Hamburg, Germany) in the clinical laboratory at the First Affiliated Hospital of Shihezi University School of Medicine.

The circulating levels of interleukin- (IL-) 6 were determined using ELISA kits (Shanghai Westang Bio-Tech Co. Ltd.). Adiponectin levels were determined using ELISA kits (Phoenix Pharmaceuticals Inc., Belmont, CA, USA). All procedures described in the manufacturer's instructions were followed with quality control parameters within the expected range recommended by the manufacturer. Every tenth sample was duplicated on the same plate. The minimum detectable concentration of IL- 6 kit is $0.8 \mathrm{pg} / \mathrm{mL}$ with the intra-assay CV $<3 \%$ and the interassay $\mathrm{CV}<6.9 \%$. The minimum detectable concentration of adiponectin kit is $0.15 \mathrm{ng} / \mathrm{mL}$, with the intraassay $\mathrm{CV}$ ranged from 3 to $6 \%$ and the interassay $\mathrm{CV}<$ $10 \%$. Insulin level was measured by radioimmunoassay. The HOMA-IR index was defined as follows: fasting insulin (in micro-international units $(\mu \mathrm{IU})$ per $\mathrm{mL}) \times \mathrm{FBG}($ in $\mathrm{mM}) / 22.5$ [7].

2.4. Definition of MetS. MetS was defined using the International Diabetes Federation (IDF) criteria [24], which include central obesity (waist circumference $\geq 90 \mathrm{~cm}$ in men or $\geq 80 \mathrm{~cm}$ in women, Chinese population waist circumference cutoffs [25]) plus any 2 of the following 4 factors: elevated TG level $(>150 \mathrm{mg} / \mathrm{dL}$ or $1.69 \mathrm{mmol} / \mathrm{L})$; reduced HDL-C $(<40 \mathrm{mg} / \mathrm{dL}$ or $1.04 \mathrm{mmol} / \mathrm{L}$ in $\mathrm{men} ;<50 \mathrm{mg} / \mathrm{dL}$ or $1.29 \mathrm{mmol} / \mathrm{L}$ in women); elevated systolic BP $(\geq 130 \mathrm{mmHg})$ or diastolic BP ( $\geq 85 \mathrm{mmHg})$; and elevated FBG $(\geq 100 \mathrm{mg} / \mathrm{dL})$.

MetS was also defined using the revised National Cholesterol Education Program Adult Treatment Panel III (NCEPATP III) criteria [26], which have any three or more of the following: waist circumference $\geq 90 \mathrm{~cm}$ in men or $\geq 80 \mathrm{~cm}$ in women (Chinese population waist circumference cutoffs [25]); triglyceride level $\geq 150 \mathrm{mg} / \mathrm{dL}$ or taking medication for increased triglycerides; high-density lipoprotein cholesterol (HDL-C) level $<40 \mathrm{mg} / \mathrm{dL}$ or taking medication to improve HDL-C; systolic blood pressure $\geq 130 \mathrm{mmHg}$ or diastolic blood pressure $\geq 85 \mathrm{mmHg}$ or taking antihypertensive agent; fasting glucose level $\geq 100 \mathrm{mg} / \mathrm{dL}$ or taking blood glucoselowering agent.

2.5. Statistical Analysis. Continuous variables are presented as mean \pm standard deviation (SD) for clinical characteristics or median (interquartile range) for IL-6, adiponectin, and fasting insulin levels. These variables were compared using unpaired $t$-tests or Mann-Whitney $U$ tests. The partial correlation coefficient was used to analyze the association between adiponectin, HOMA-IR, $\mathrm{A} / \mathrm{H}$ ratio, and other continuous variables of interest, controlling for the effect of age. Multivariable logistic regression analysis with MetS as the dichotomous dependent variable was conducted to determine the association between adiponectin, HOMA-IR, $\mathrm{A} / \mathrm{H}$ ratio, and MetS. The resulting odds ratios (ORs) and $95 \%$ confidence intervals (CIs) are reported. The receiver operating characteristic (ROC) analyses were used to describe the ability of the adiponectin, HOMA-IR, and $\mathrm{A} / \mathrm{H}$ ratio to differentiate between subjects with and without metabolic syndrome. ROC analyses were also used to evaluate the 
TABLE 1: General characteristics of the study participants according to presence or absence of MetS.

\begin{tabular}{|c|c|c|c|c|c|c|}
\hline \multirow[b]{2}{*}{ Parameters } & \multicolumn{3}{|c|}{$\operatorname{Men}(n=768)$} & \multicolumn{3}{|c|}{ Women $(n=860)$} \\
\hline & $\begin{array}{l}\text { Without MetS } \\
\quad(n=504)\end{array}$ & $\begin{array}{c}\text { With MetS } \\
(n=264)\end{array}$ & $p$ & $\begin{array}{l}\text { Without MetS } \\
\quad(n=593)\end{array}$ & $\begin{array}{c}\text { With MetS } \\
(n=267)\end{array}$ & $p$ \\
\hline \multicolumn{7}{|l|}{ Anthropometric characteristics } \\
\hline Age $(y)$ & $44.44 \pm 13.98$ & $50.34 \pm 11.47$ & $<0.01$ & $40.17 \pm 12.25$ & $49.38 \pm 11.48$ & $<0.01$ \\
\hline Waist circumference $(\mathrm{cm})$ & $83.07 \pm 9.31$ & $99.14 \pm 8.17$ & $<0.01$ & $77.46 \pm 9.67$ & $91.52 \pm 8.27$ & $<0.01$ \\
\hline $\operatorname{BMI}\left(\mathrm{kg} / \mathrm{m}^{2}\right)$ & $23.10 \pm 3.09$ & $28.60 \pm 3.37$ & $<0.01$ & $22.60 \pm 3.43$ & $27.39 \pm 3.65$ & $<0.01$ \\
\hline Systolic BP (mmHg) & $126.80 \pm 21.61$ & $144.60 \pm 20.34$ & $<0.01$ & $122.60 \pm 19.89$ & $144.73 \pm 25.60$ & $<0.01$ \\
\hline Diastolic BP (mmHg) & $81.59 \pm 13.33$ & $92.39 \pm 12.12$ & $<0.01$ & $78.72 \pm 12.26$ & $92.03 \pm 12.85$ & $<0.01$ \\
\hline Current smoker $(n[\%])$ & $258(51.29 \%)$ & $214(81.06 \%)$ & $<0.01$ & $231(38.89 \%)$ & $214(80.15 \%)$ & $<0.01$ \\
\hline \multicolumn{7}{|l|}{ Metabolic characteristics } \\
\hline Total cholesterol (mmol/L) & $4.14 \pm 0.98$ & $4.75 \pm 1.23$ & $<0.01$ & $4.13 \pm 1.08$ & $4.57 \pm 1.28$ & $<0.01$ \\
\hline $\mathrm{TG}(\mathrm{mmol} / \mathrm{L})$ & $1.01 \pm 0.48$ & $2.06 \pm 1.30$ & $<0.01$ & $0.93 \pm 0.42$ & $1.55 \pm 0.87$ & $<0.01$ \\
\hline HDL cholesterol (mmol/L) & $1.42 \pm 0.42$ & $1.38 \pm 0.57$ & $<0.01$ & $1.60 \pm 0.43$ & $1.31 \pm 0.49$ & $<0.01$ \\
\hline LDL cholesterol (mmol/L) & $2.19 \pm 0.69$ & $2.53 \pm 0.97$ & $<0.01$ & $2.05 \pm 0.69$ & $2.49 \pm 0.82$ & $<0.01$ \\
\hline $\mathrm{FBG}(\mathrm{mmol} / \mathrm{L})$ & $4.47 \pm 0.93$ & $5.57 \pm 1.47$ & $<0.01$ & $4.28 \pm 0.79$ & $5.19 \pm 1.22$ & $<0.01$ \\
\hline Insulin $(\mu \mathrm{IU} / \mathrm{dL})$ & $10.80(7.01-14.72)$ & $14.95(12.30-17.00)$ & $<0.01$ & $9.60(7.20-15.50)$ & $14.61(8.40-17.50)$ & $<0.01$ \\
\hline HOMA-IR & $2.05(1.32-3.00)$ & $3.31(2.47-4.54)$ & $<0.01$ & $1.81(1.37-3.08)$ & $3.28(1.77-4.31)$ & $<0.01$ \\
\hline Adiponectin $(\mu \mathrm{g} / \mathrm{mL})$ & $5.78(4.18-6.63)$ & $4.04(2.67-5.65)$ & $<0.01$ & $6.98(5.43-8.40)$ & $5.70(3.93-8.12)$ & $<0.05$ \\
\hline $\mathrm{A} / \mathrm{H}$ ratio & $2.43(1.50-3.95)$ & $1.08(0.75-1.91)$ & $<0.01$ & $3.30(2.08-5.00)$ & $2.02(1.00-3.57)$ & $<0.01$ \\
\hline IL-6 (pg/mL) & $0.65(0.16-1.39)$ & $1.58(1.18-1.97)$ & $<0.01$ & $0.53(0.15-1.33)$ & $1.60(0.99-2.01)$ & $<0.01$ \\
\hline
\end{tabular}

Values are expressed as means \pm SD or number (\%), if not stated otherwise. Median values of adiponectin, fasting insulin, IL-6, and HOMA-IR are presented (lower quartile-upper quartile).

SD, standard deviation; BMI, body mass index; TG, triglyceride; BP, blood pressure; HDL, high-density lipoprotein; LDL, low-density lipoprotein; FBG, fasting blood glucose; HOMA-IR, homeostasis model assessment of insulin resistance; IL-6, interleukin-6; A/H ratio, adiponectin to homeostasis assessment-insulin resistance.

difference in the contribution of the adiponectin, HOMA-IR, and $\mathrm{A} / \mathrm{H}$ ratio to the risk levels of each component of MetS. All analyses were performed using SPSS v17.0 for Windows (SPSS Inc., Chicago, IL, USA). Differences with a $p$ value of $<0.05$ were considered statistically significant.

\section{Results}

The characteristics of the study population, based on sex and presence of MetS, are provided in Table 1. IL-6 levels, insulin levels, HOMA-IR, and other anthropometric and metabolic characteristics were significantly greater in the MetS group than in the non-MetS group in both men and women $(p<$ $0.05)$. In contrast, adiponectin levels, the $\mathrm{A} / \mathrm{H}$ ratio, and HDL-C levels were significantly lower in the MetS group than in the non-MetS group $(p<0.05)$.

The correlations between the adiponectin levels, HOMA$\mathrm{IR}$, and $\mathrm{A} / \mathrm{H}$ ratio and the risk factors of MetS are presented in Table 2. Adiponectin levels and the $\mathrm{A} / \mathrm{H}$ ratio were negatively correlated with waist circumference, BMI, TC, TG, FBG, insulin, IL-6, and HOMA-IR (all $p<0.05$ ). The correlation coefficients for BMI, waist circumference, TG, FBG, LDL, insulin, IL-6, and HOMA-IR with the A/H ratio were higher than those with adiponectin.

The multivariable adjusted ORs (95\% CI) showed that the highest quartiles of adiponectin, HOMA-IR, and the A/H ratio were significantly associated with MetS, compared with the lowest quartiles (Table 3). In models I, II, and III, the adjusted ORs for MetS were higher with the $\mathrm{A} / \mathrm{H}$ ratio than with adiponectin. In model III, which was adjusted for sex, age, smoking status, LDL-C, TC, and HDL-C, adiponectin (OR, 0.30; 95\% CI, 0.19-0.46), HOMA-IR (OR, 3.82; 95\% $\mathrm{CI}, 2.42-6.04$ ), and $\mathrm{A} / \mathrm{H}$ ratio (OR, 0.25; 95\% CI, 0.15-0.40) remained significantly associated with MetS.

Receiver operating characteristic (ROC) analysis was performed to detect the performance of the adiponectin, HOMA-IR, and $\mathrm{A} / \mathrm{H}$ ratio as a diagnostic marker for MetS defined by the IDF and ATP III (Figure 1). As Figure 1 shows, the area under curve (AUC) of the $\mathrm{A} / \mathrm{H}$ ratio, HOMAIR, and adiponectin to detect MetS was $0.727,0.707$, and 0.639 , respectively, by IDF criteria and $0.773,0.747$, and 0.715 , respectively, by ATP III criteria. In addition we estimated that the best cutoff value for the $\mathrm{A} / \mathrm{H}$ ratio to identify a risk of MetS was 2.10 (sensitivity, 0.68; specificity, 0.67), by IDF criteria. We estimated that the best cutoff value for the $\mathrm{A} / \mathrm{H}$ ratio to identify a risk of MetS was 1.89 (sensitivity, 0.76; specificity, 0.67), by ATP III criteria.

The adjusted ORs (95\% CI) and AUC to detect the MetS components are shown in Table 4. After adjustment for age, BMI, smoking status, and LDL-C, adiponectin, HOMA-IR, and the A/H ratio were all significantly associated with the MetS components. Except for BP, the ORs for the MetS components were lower for the $\mathrm{A} / \mathrm{H}$ ratio than for adiponectin. Except for low HDL and abnormal glucose, the 
TABLE 2: Partial correlation analysis among adiponectin, HOMA-IR, $\mathrm{A} / \mathrm{H}$ ratio, and risk factors of MetS.

\begin{tabular}{|c|c|c|c|}
\hline & & & \\
\hline $\begin{array}{l}\text { Waist } \\
\text { circumfere }\end{array}$ & $-0.220(<0.001)$ & $-0.212(<0.001)$ & $-0.210(<0.00$ \\
\hline $\mathrm{BMI}$ & $-0.259(<0.001)$ & $-0.254(<0.001)$ & $-0.222(<0.00$ \\
\hline Systo & $-0.056(0.025)$ & $-0.121(<0.001)$ & $0.050(0.043)$ \\
\hline Diastolic BP & $-0.085(0.001)$ & $-0.132(<0.001)$ & $0.071(0.004)$ \\
\hline Total cholesterol & $-0.076(0.002)$ & $-0.089(<0.001)$ & 0.212 \\
\hline TG & $-0.172(<0.001)$ & $-0.016(<0.001)$ & $0.222(<0.001)$ \\
\hline HDL & $0.047(<0.058)$ & & \\
\hline LDL cholesterol & $-0.069(<0.001)$ & $-0.055(0.026)$ & $0.212(<0.001)$ \\
\hline FBG & $-0.261(<0.001)$ & $-0.091(<0.001)$ & $0.398(<0.001)$ \\
\hline Insulin & $-0.485(<0.001)$ & $-0.059(0.017)$ & $0.875(<0.001)$ \\
\hline IL-6 & $-0.159(<0.001)$ & $-0.082(0.001)$ & $0.151(<0.001)$ \\
\hline Adiponectin & $0.618(<0.001)$ & - & $-0.112(<0.001)$ \\
\hline HOMA-IR & $-0.521(<0.001)$ & $-0.112(<0.001)$ & - \\
\hline $\mathrm{A} / \mathrm{H}$ ratio & - & $0.618(<0.001)$ & $-0.521(<0.001)$ \\
\hline
\end{tabular}

Values are age- and gender-adjusted Spearman correlation coefficients and $p$ values for correlations of adiponectin, HOMA-IR, and $\mathrm{A} / \mathrm{H}$ ratio with risk factors of MetS.

BMI, body mass index; BP, blood pressure; TG, triglyceride; HDL, highdensity lipoprotein; LDL, low-density lipoprotein; FBG, fasting blood glucose; HOMA-IR, homeostasis assessment-insulin resistance; $\mathrm{A} / \mathrm{H}$ ratio, adiponectin to homeostasis assessment-insulin resistance; MetS, metabolic syndrome.

AUCs of the MetS components were higher for the $\mathrm{A} / \mathrm{H}$ ratio than for adiponectin and HOMA-IR.

\section{Discussion}

In this study, we found that the $\mathrm{A} / \mathrm{H}$ ratio is more strongly associated with MetS and most of the MetS components than adiponectin. In addition, the $\mathrm{A} / \mathrm{H}$ ratio showed greater predictive power than adiponectin and HOMA-IR for the risk of MetS. The A/H ratio is better at correctly classifying subjects with and without MetS than adiponectin or HOMAIR alone.

Adiponectin is a multifunctional protein with pleiotropic insulin-sensitizing effects and is considered a key molecule in the pathogenesis of MetS $[16,27,28]$. In the present study, adiponectin levels were negatively correlated with waist circumference, BMI, TC, TG, FBG, insulin, IL-6, and HOMA-IR (all $p<0.05$ ); when adjusted for sex, age, smoking status, and LDL-C, adiponectin remained significantly associated with MetS and MetS components. These findings are consistent with those of previous reports [21, 29]. Our previous results suggest that decreased adiponectin levels and HOMA-IR might be associated with IR and can predict the course of MetS [30].

The $\mathrm{A} / \mathrm{H}$ ratio was significantly lower in the MetS group than in the non-MetS group $(p<0.05)$. Furthermore, the $\mathrm{A} / \mathrm{H}$ ratio was significantly associated with MetS and MetS
TABLE 3: Odds ratios and 95\% confidence intervals for the association between metabolic syndrome and various markers.

\begin{tabular}{|c|c|c|c|}
\hline & \multicolumn{3}{|c|}{ Odds ratio $(95 \% \mathrm{CI})$} \\
\hline & Model I & Model II & Model III \\
\hline \multicolumn{4}{|l|}{ Adiponectin } \\
\hline 1st quartile & 1 & 1 & 1 \\
\hline 2nd quartile & $\begin{array}{c}0.59 \\
(0.44-0.79)\end{array}$ & $\begin{array}{c}0.65 \\
(0.44-0.95)\end{array}$ & $\begin{array}{c}0.66 \\
(0.44-0.99)\end{array}$ \\
\hline 3rd quartile & $\begin{array}{c}0.29 \\
(0.21-0.40)\end{array}$ & $\begin{array}{c}0.58 \\
(0.37-0.89)\end{array}$ & $\begin{array}{c}0.60 \\
(0.38-0.95)\end{array}$ \\
\hline 4th quartile & $\begin{array}{c}0.28 \\
(0.20-0.40)\end{array}$ & $\begin{array}{c}0.34 \\
(0.23-0.51)\end{array}$ & $\begin{array}{c}0.30 \\
(0.19-0.46)\end{array}$ \\
\hline \multicolumn{4}{|l|}{ HOMA-IR } \\
\hline 1st quartile & 1 & 1 & 1 \\
\hline 2nd quartile & $\begin{array}{c}1.63 \\
(1.11-2.32)\end{array}$ & $\begin{array}{c}1.62 \\
(1.04-2.52)\end{array}$ & $\begin{array}{c}1.72 \\
(1.08-2.73)\end{array}$ \\
\hline 3rd quartile & $\begin{array}{c}2.88 \\
(2.02-4.10)\end{array}$ & $\begin{array}{c}2.05 \\
(1.33-3.16)\end{array}$ & $\begin{array}{c}1.83 \\
(1.16-2.88)\end{array}$ \\
\hline 4th quartile & $\begin{array}{c}7.36 \\
(5.19-10.46)\end{array}$ & $\begin{array}{c}3.88 \\
(2.52-5.97)\end{array}$ & $\begin{array}{c}3.82 \\
(2.42-6.04)\end{array}$ \\
\hline \multicolumn{4}{|l|}{$\mathrm{A} / \mathrm{H}$ ratio } \\
\hline 1st quartile & 1 & 1 & 1 \\
\hline 2nd quartile & $\begin{array}{c}0.30 \\
(0.22-0.40)\end{array}$ & $\begin{array}{c}0.53 \\
(0.35-0.80)\end{array}$ & $\begin{array}{c}0.52 \\
(0.33-0.83)\end{array}$ \\
\hline 3rd quartile & $\begin{array}{c}0.25 \\
(0.18-0.16)\end{array}$ & $\begin{array}{c}0.41 \\
(0.28-0.60)\end{array}$ & $\begin{array}{c}0.43 \\
(0.28-0.66)\end{array}$ \\
\hline 4th quartile & $\begin{array}{c}0.11 \\
(0.08-0.16)\end{array}$ & $\begin{array}{c}0.23 \\
(0.15-0.35)\end{array}$ & $\begin{array}{c}0.25 \\
(0.15-0.40)\end{array}$ \\
\hline
\end{tabular}

CI, confidence interval; HOMA-IR, homeostasis model assessment of insulin resistance; $\mathrm{A} / \mathrm{H}$ ratio, adiponectin to homeostasis assessment-insulin resistance; MetS, metabolic syndrome; IL-6, interleukin-6.

Model I: adjusted for sex and age.

Model II: adjusted for sex, age, body mass index, smoking status, and lowdensity lipoprotein cholesterol.

Model III: adjusted for sex, age, body mass index, smoking status, lowdensity lipoprotein cholesterol, total cholesterol, and high-density lipoprotein cholesterol.

components after adjustment for sex, age, smoking status, and LDL-C. These results support the suggestion that the $\mathrm{A} / \mathrm{H}$ ratio could be a powerful index for the evaluation of MetS [23]. However, there are few studies that have compared the strength of the associations between MetS and adiponectin and the $\mathrm{A} / \mathrm{H}$ ratio or the ability of the $\mathrm{A} / \mathrm{H}$ ratio to classify subjects with and without MetS. It is important to clarify the diagnostic power of adiponectin and the $\mathrm{A} / \mathrm{H}$ ratio for future clinical use.

In our study, the $\mathrm{A} / \mathrm{H}$ ratio showed a greater predicting power than adiponectin. For example, the correlation coefficients for BMI, waist circumference, TG, FBG, LDL, insulin, IL-6, and HOMA-IR with the A/H ratio were higher than those with adiponectin. Except for BP, the ORs for MetS and MetS components were lower for the $\mathrm{A} / \mathrm{H}$ ratio than for adiponectin. We also conducted ROC analyses with the same participants using the IDF and updated ATP III definition for MetS, and the AUCs of the A/H ratio were higher than those for adiponectin and HOMA-IR by IDF and updated ATP III 
TABLE 4: Odds ratios (95\% CI) and ROC analysis for the association between each component of MetS and markers.

\begin{tabular}{|c|c|c|c|c|c|c|}
\hline & \multicolumn{2}{|c|}{ Adiponectin (Q4 versus Q1) } & \multicolumn{2}{|c|}{ HOMA-IR (Q4 versus Q1) } & \multicolumn{2}{|c|}{$\mathrm{A} / \mathrm{H}$ ratio $(\mathrm{Q} 4$ versus $\mathrm{Q} 1)$} \\
\hline & $\mathrm{OR}^{*}(95 \% \mathrm{CI})$ & AUC (SE) & $\mathrm{OR}^{*}(95 \% \mathrm{CI})$ & AUC (SE) & $\mathrm{OR}^{*}(95 \% \mathrm{CI})$ & $\mathrm{AUC}(\mathrm{SE})$ \\
\hline Abdominal obesity & $0.37(0.27-0.51)$ & $0.58(0.01)$ & $2.74(2.01-3.72)$ & $0.61(0.01)$ & $0.20(0.13-0.31)$ & $0.63(0.01)$ \\
\hline High triglycerides & $0.42(0.28-0.65)$ & $0.64(0.02)$ & $4.35(2.82-6.71)$ & $0.67(0.02)$ & $0.20(0.13-0.31)$ & $0.69(0.02)$ \\
\hline High blood pressure & $0.33(0.24-0.46)$ & $0.61(0.01)$ & $1.55(1.14-2.10)$ & $0.55(0.01)$ & $0.44(0.33-0.59)$ & $0.61(0.01)$ \\
\hline Low HDL & $0.71(0.51-0.99)$ & $0.51(0.02)$ & $1.74(1.25-2.42)$ & $0.57(0.02)$ & $0.50(0.36-0.69)$ & $0.55(0.02)$ \\
\hline Abnormal glucose & $0.42(0.28-0.63)$ & $0.63(0.02)$ & $10.08(6.32-16.06)$ & $0.75(0.02)$ & $0.14(0.09-0.23)$ & $0.73(0.02)$ \\
\hline
\end{tabular}

$\mathrm{CI}$, confidence interval; AUC, area under the curve; SE, standard error; A/H ratio, adiponectin to homeostasis assessment-insulin resistance; MetS, metabolic syndrome; Q4, highest quartile; Q1, lowest quartile.

*Adjusted for sex, age, smoking status, and LDL cholesterol.
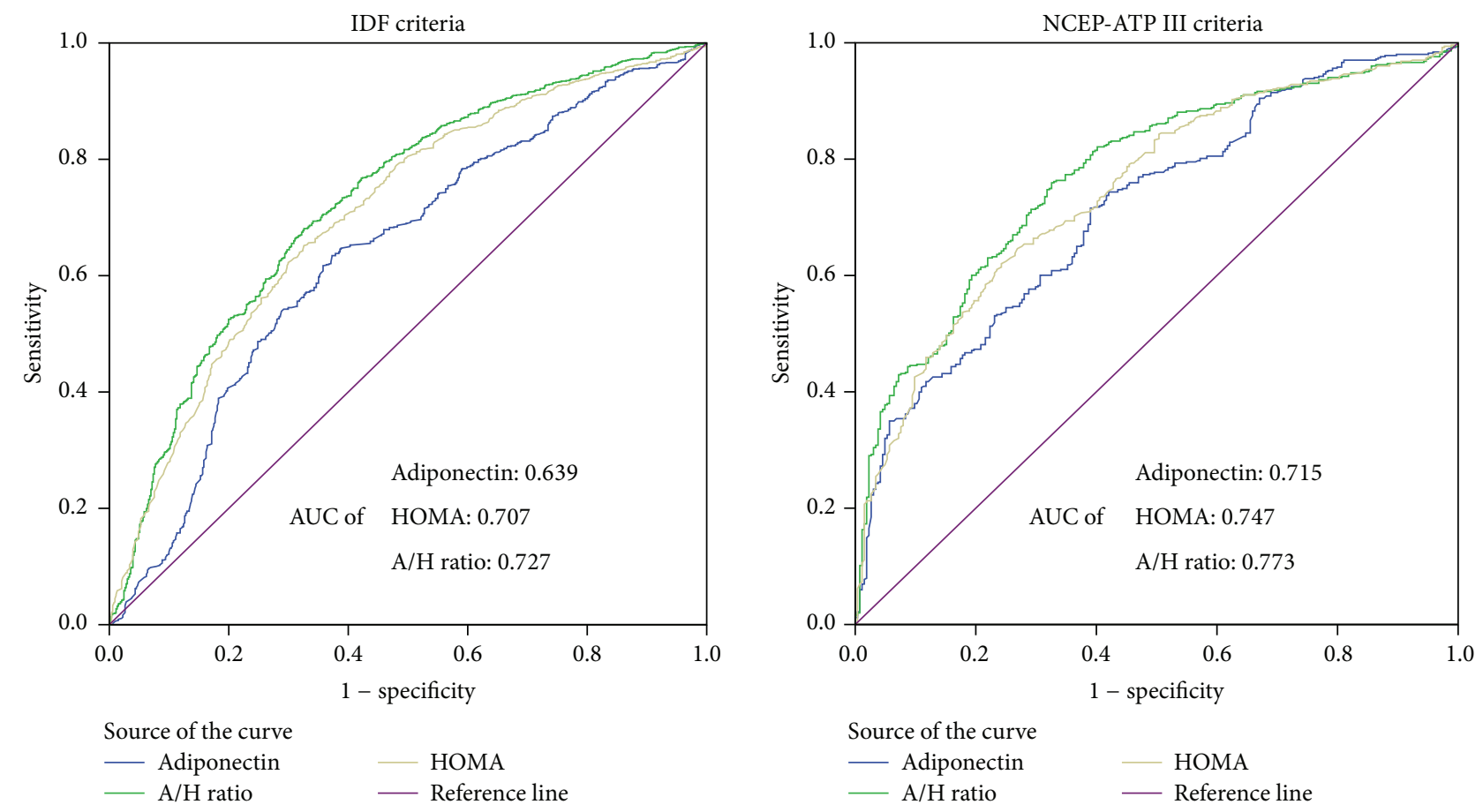

FIGURE 1: Comparison of predicting powers between adiponectin, HOMA-IR, and A/H ratio for difference metabolic syndrome criteria. HOMA-IR, homeostasis model assessment of insulin resistance; A/H ratio, adiponectin to homeostasis assessment-insulin resistance; ROC, receiver operating characteristic; AUC, area under the curve; IDF, International Diabetes Federation; NCEP-ATP III, National Cholesterol Education Program Adult Treatment Panel III.

definition. In addition, except for low HDL and abnormal glucose, the AUCs of the MetS components were also higher for the $\mathrm{A} / \mathrm{H}$ ratio than for adiponectin and HOMA-IR.

We performed the additional analysis to obtain the best cutoff for IDF and updated ATP III definition. We estimated that the best value for the $\mathrm{A} / \mathrm{H}$ ratio to identify a risk of MetS was 2.10 (sensitivity, 0.68 ; specificity, 0.67 ), by IDF criteria. We estimated that the best cutoff value for the $\mathrm{A} / \mathrm{H}$ ratio to identify a risk of MetS was 1.89 (sensitivity, 0.76; specificity, 0.67 ), by ATP III criteria. The $\mathrm{A} / \mathrm{H}$ ratio has similar values of sensitivity and specificity with leptin/adiponectin ratio [25, 31].

These results could further explain our finding that the $\mathrm{A} / \mathrm{H}$ ratio has a significant adjunctive contribution, beyond that of the adiponectin and HOMA-IR alone, to metabolic syndrome.
This study had several limitations. First, the crosssectional design was not able to determine a causal relationship between MetS or its components and adiponectin HOMA-IR and A/H ratio. Second, we did not evaluate high molecular weight adiponectin, which is considered to be more useful than total adiponectin in evaluating the MetS and IR $[31,32]$. Further investigation regarding the role of the ratio of high molecular weight adiponectin and HOMA-IR in MetS is needed.

In conclusion, to the best of our knowledge, this was the first large-scale population-based study to compare the diagnostic efficiency of adiponectin, HOMA-IR, and the A/H ratio in healthy middle-aged participants. We demonstrated that the $\mathrm{A} / \mathrm{H}$ ratio can act as a marker of MetS and its components, serving as an important surrogate biomarker for MetS risk, and the $\mathrm{A} / \mathrm{H}$ ratio contributed more to MetS 
than either HOMA-IR or adiponectin alone. As a result, this study provides useful information for clinicians to identify individuals at high risk of MetS. These results also show that the $\mathrm{A} / \mathrm{H}$ ratio is helpful in understanding cardiometabolic diseases.

$\begin{array}{ll}\text { Abbreviations } \\ \text { BMI: } & \text { Body mass index } \\ \text { BP: } & \text { Blood pressure } \\ \text { TC: } & \text { Total cholesterol } \\ \text { TG: } & \text { Triglyceride } \\ \text { HDL: } & \text { High-density lipoprotein } \\ \text { LDL: } & \text { Low-density lipoprotein } \\ \text { FBG: } & \text { Fasting blood glucose } \\ \text { HOMA-IR: } & \text { Homeostasis assessment-insulin resistance } \\ \text { A/H ratio: } & \text { Adiponectin to homeostasis } \\ & \text { assessment-insulin resistance } \\ \text { MetS: } & \text { Metabolic syndrome } \\ \text { ORs: } & \text { Odds ratios } \\ \text { CIs: } & \text { Confidence intervals } \\ \text { ROC: } & \text { Receiver operating characteristic } \\ \text { AUC: } & \text { Area under the curve } \\ \text { IL-6: } & \text { Interleukin-6. }\end{array}$

\section{Disclosure}

The funders had no role in study design, data collection and analysis, decision to publish, or preparation of the paper.

\section{Conflict of Interests}

None of the authors have any potential conflict of interests associated with this research.

\section{Authors' Contribution}

Shu-Xia Guo and Lie-Gang Liu conceived and designed the experiments. Yu-Song Ding, Ru-Lin Ma, Heng Guo, Jing-Yu Zhang, Mei Zhang, Jia-Ming Liu, and Shu-Gang Li performed the experiments. Yu-Song Ding analyzed and interpreted the data. Yu-Song Ding, Shu-Xia Guo, and WenJie Zhang wrote the paper.

\section{Acknowledgments}

The authors sincerely thank those who participated in the study. They are grateful to the Xinyuan County Government, County Health Bureau, and their employees for field assistance. This work was supported by National Natural Science Foundation of China (no. 81560551), Chinese Ministry of Science and Technology (no. 2009BAI82B04), and the Medical and Health Research Fund of Xinjiang Production and Construction Corps (2011BA037).

\section{References}

[1] O. H. Del Brutto, R. M. Mera, M. Montalván et al., "Cardiovascular health status and metabolic syndrome in Ecuadorian natives/mestizos aged 40 years or more with and without stroke and ischemic heart disease - an Atahualpa project case-control nested study," Journal of Stroke \& Cerebrovascular Diseases, vol. 23, no. 4, pp. 643-648, 2014.

[2] T. M. Ahonen, J. T. Saltevo, H. J. Kautiainen, E. A. Kumpusalo, and M. J. Vanhala, "The association of adiponectin and lowgrade inflammation with the course of metabolic syndrome," Nutrition, Metabolism and Cardiovascular Diseases, vol. 22, no. 3, pp. 285-291, 2012.

[3] S. M. Grundy, "Metabolic syndrome pandemic," Arteriosclerosis, Thrombosis, and Vascular Biology, vol. 28, no. 4, pp. 629-636, 2008.

[4] J. Kaur, "A comprehensive review on metabolic syndrome," Cardiology Research and Practice, vol. 2014, Article ID 943162, 21 pages, 2014.

[5] M. J. Blaha, S. Bansal, R. Rouf, S. H. Golden, R. S. Blumenthal, and A. P. DeFilippis, "A practical "ABCDE" approach to the metabolic syndrome," Mayo Clinic Proceedings, vol. 83, no. 8, pp. 932-943, 2008.

[6] P. M. Siu and Q. S. Yuen, "Supplementary use of HbAlc as hyperglycemic criterion to detect metabolic syndrome," Diabetology \& Metabolic Syndrome, vol. 6, article 119, 2014.

[7] N. Sattar, A. McConnachie, A. G. Shaper et al., "Can metabolic syndrome usefully predict cardiovascular disease and diabetes? Outcome data from two prospective studies," The Lancet, vol. 371, no. 9628, pp. 1927-1935, 2008.

[8] B. Singh, S. Arora, B. Goswami, and V. Mallika, "Metabolic syndrome: a review of emerging markers and management," Diabetes \& Metabolic Syndrome: Clinical Research \& Reviews, vol. 3, no. 4, pp. 240-254, 2009.

[9] A. Lee, H. B. Jang, M. Ra et al., "Prediction of future risk of insulin resistance and metabolic syndrome based on Korean boy's metabolite profiling," Obesity Research \& Clinical Practice, vol. 9, no. 4, pp. 336-345, 2015.

[10] J.-H. Yoon, J. K. Park, S. S. Oh et al., "The ratio of serum leptin to adiponectin provides adjunctive information to the risk of metabolic syndrome beyond the homeostasis model assessment insulin resistance: the Korean Genomic Rural Cohort Study," Clinica Chimica Acta, vol. 412, no. 23-24, pp. 2199-2205, 2011.

[11] S. Guo, "Insulin signaling, resistance, and metabolic syndrome: insights from mouse models into disease mechanisms," The Journal of Endocrinology, vol. 220, no. 2, pp. T1-T23, 2014.

[12] H. Kimm, S. W. Lee, H. S. Lee et al., "Associations between lipid measures and metabolic syndrome, insulin resistance and adiponectin," Circulation Journal, vol. 74, no. 5, pp. 931-937, 2010.

[13] D. R. Matthews, J. P. Hosker, A. S. Rudenski, B. A. Naylor, D. F. Treacher, and R. C. Turner, "Homeostasis model assessment: insulin resistance and beta-cell function from fasting plasma glucose and insulin concentrations in man," Diabetologia, vol. 28, no. 7, pp. 412-419, 1985.

[14] S. M. Haffner, E. Kennedy, C. Gonzalez, M. P. Stern, and H. Miettinen, "A prospective analysis of the homa model: the mexico city diabetes study," Diabetes Care, vol. 19, no. 10, pp. 1138-1141, 1996.

[15] Y. Cao, T. Yang, S. Yu, G. Sun, C. Gu, and D. Yi, "Relationships of adiponectin with markers of systemic inflammation and insulin resistance in infants undergoing open cardiac surgery," 
Mediators of Inflammation, vol. 2013, Article ID 187940, 6 pages, 2013.

[16] A. Yadav, M. A. Kataria, V. Saini, and A. Yadav, "Role of leptin and adiponectin in insulin resistance," Clinica Chimica Acta, vol. 417, pp. 80-84, 2013.

[17] K. Ohashi, D. Yuasa, R. Shibata, T. Murohara, and N. Ouchi, "Adiponectin as a target in obesity-related inflammatory state," Endocrine, Metabolic \& Immune Disorders-Drug Targets, vol. 15, no. 2, pp. 145-150, 2015.

[18] R. Timar, B. Timar, D. Degeratu, C. Serafinceanu, and C. Oancea, "Metabolic syndrome, adiponectin and proinflammatory status in patients with type 1 diabetes mellitus," The Journal of International Medical Research, vol. 42, no. 5, pp. 1131-1138, 2014.

[19] C. Herder, D. M. Ouwens, M. Carstensen et al., "Adiponectin may mediate the association between omentin, circulating lipids and insulin sensitivity: results from the KORA F4 Study," European Journal of Endocrinology, vol. 172, no. 4, pp. 423-432, 2015.

[20] H. Chen, L. Zhang, X. Li et al., "Adiponectin activates the AMPK signaling pathway to regulate lipid metabolism in bovine hepatocytes," The Journal of Steroid Biochemistry and Molecular Biology, vol. 138, pp. 445-454, 2013.

[21] S.-B. Koh, J. Yoon, J.-Y. Kim et al., "Relationships between serum adiponectin with metabolic syndrome and components of metabolic syndrome in non-diabetic Koreans: Arirang study," Yonsei Medical Journal, vol. 52, no. 2, pp. 234-241, 2011.

[22] S.-B. Koh, J.-K. Park, J.-H. Yoon et al., "Preliminary report: a serious link between adiponectin levels and metabolic syndrome in a Korean nondiabetic population," Metabolism: Clinical and Experimental, vol. 59, no. 3, pp. 333-337, 2010.

[23] M. Nakatochi, S. Miyata, D. Tanimura et al., "The ratio of adiponectin to homeostasis model assessment of insulin resistance is a powerful index of each component of metabolic syndrome in an aged Japanese population: results from the KING Study," Diabetes Research and Clinical Practice, vol. 92, no. 3, pp. e61-e65, 2011.

[24] K. G. M. M. Alberti, P. Zimmet, and J. Shaw, "The metabolic syndrome-a new worldwide definition," The Lancet, vol. 366, no. 9491, pp. 1059-1062, 2005.

[25] Q. Zhuo, Z. Wang, P. Fu et al., "Comparison of adiponectin, leptin and leptin to adiponectin ratio as diagnostic marker for metabolic syndrome in older adults of Chinese major cities," Diabetes Research and Clinical Practice, vol. 84, no. 1, pp. 27-33, 2009.

[26] S. M. Grundy, J. I. Cleeman, S. R. Daniels et al., "Diagnosis and management of the metabolic syndrome: an American Heart Association/National Heart, Lung, and Blood Institute scientific statement," Current Opinion in Cardiology, vol. 21, no. 1, pp. 1-6, 2006.

[27] P. López-Jaramillo, D. Gómez-Arbeláez, J. López-López et al., "The role of leptin/adiponectin ratio in metabolic syndrome and diabetes," Hormone Molecular Biology and Clinical Investigation, vol. 18, no. 1, pp. 37-45, 2014.

[28] Y. Saisho, H. Hirose, R. Roberts, T. Abe, H. Kawabe, and H. Itoh, " $\mathrm{C}$-reactive protein, high-molecular-weight adiponectin and development of metabolic syndrome in the Japanese general population: a longitudinal cohort study," PLOS ONE, vol. 8, no. 9, Article ID e73430, 2013.

[29] T. Eglit, M. Lember, I. Ringmets, and T. Rajasalu, "Gender differences in serum high-molecular-weight adiponectin levels in metabolic syndrome," European Journal of Endocrinology, vol. 168, no. 3, pp. 385-391, 2013.

[30] Y. Ding, S. Li, R. L. Ma et al., "Association of homeostasis model assessment of insulin resistance, adiponectin, and low-grade inflammation with the course of the metabolic syndrome," Clinical Biochemistry, vol. 48, no. 7-8, pp. 503-507, 2015.

[31] J. E. Yun, S. Won, Y. Mok, W. Cui, H. Kimm, and S. H. Jee, "Association of the leptin to high-molecular-weight adiponectin ratio with metabolic syndrome," Endocrine Journal, vol. 58, no. 9, pp. 807-815, 2011.

[32] Y. Seino, H. Hirose, I. Saito, and H. Itoh, "High molecular weight multimer form of adiponectin as a useful marker to evaluate insulin resistance and metabolic syndrome in Japanese men," Metabolism: Clinical and Experimental, vol. 56, no. 11, pp. 14931499, 2007. 


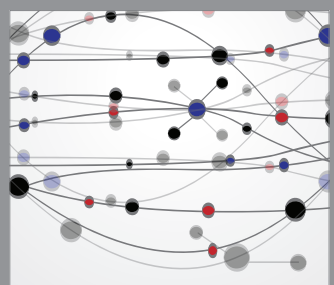

The Scientific World Journal
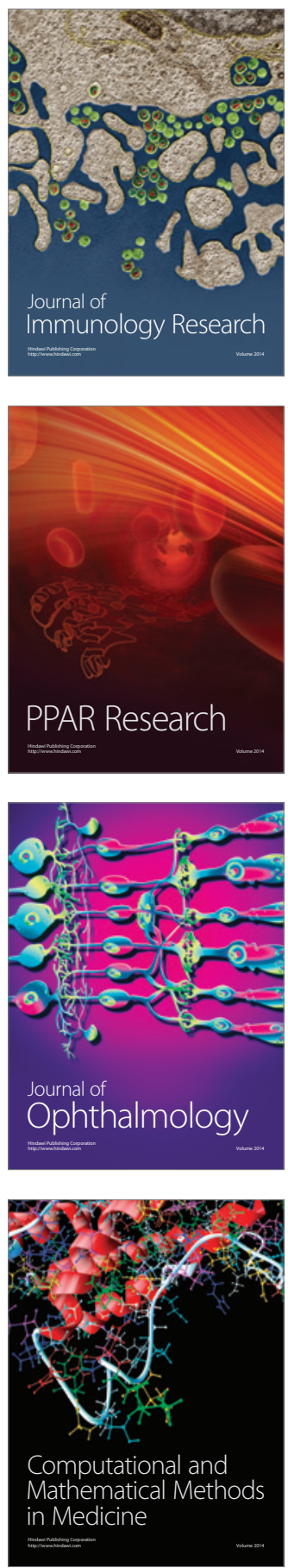

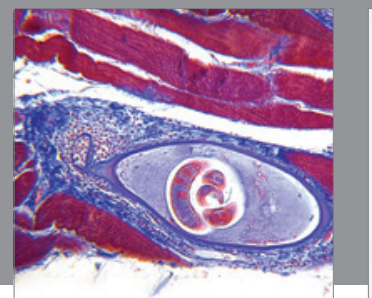

Gastroenterology

Research and Practice
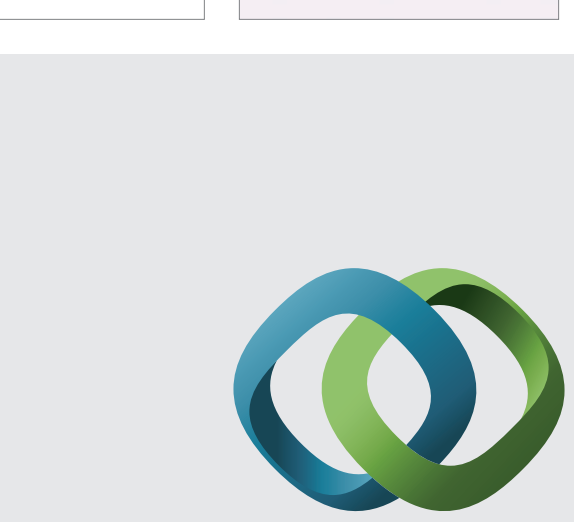

\section{Hindawi}

Submit your manuscripts at

http://www.hindawi.com
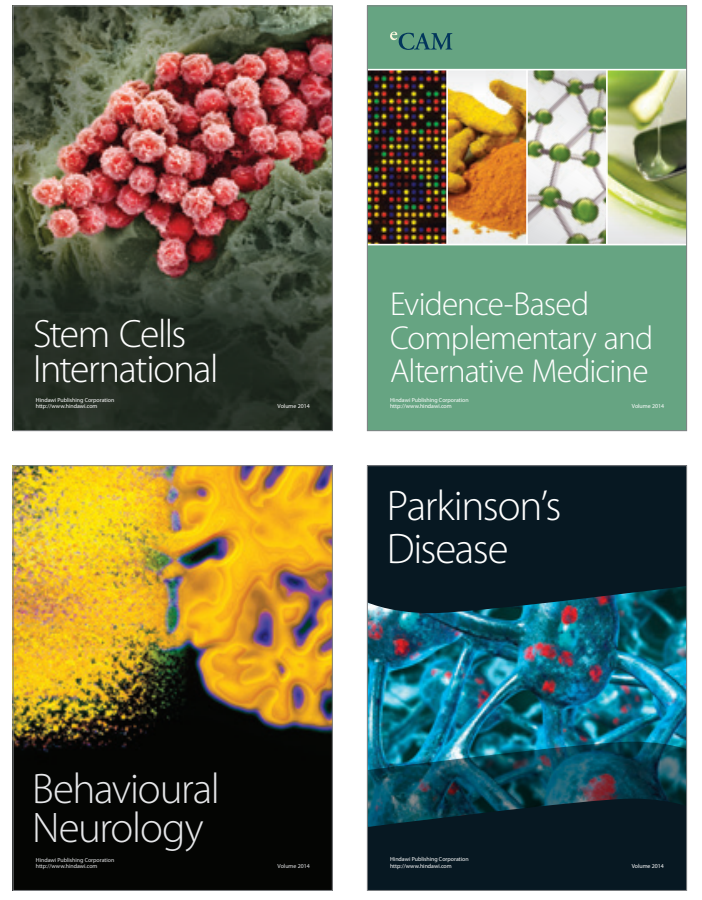
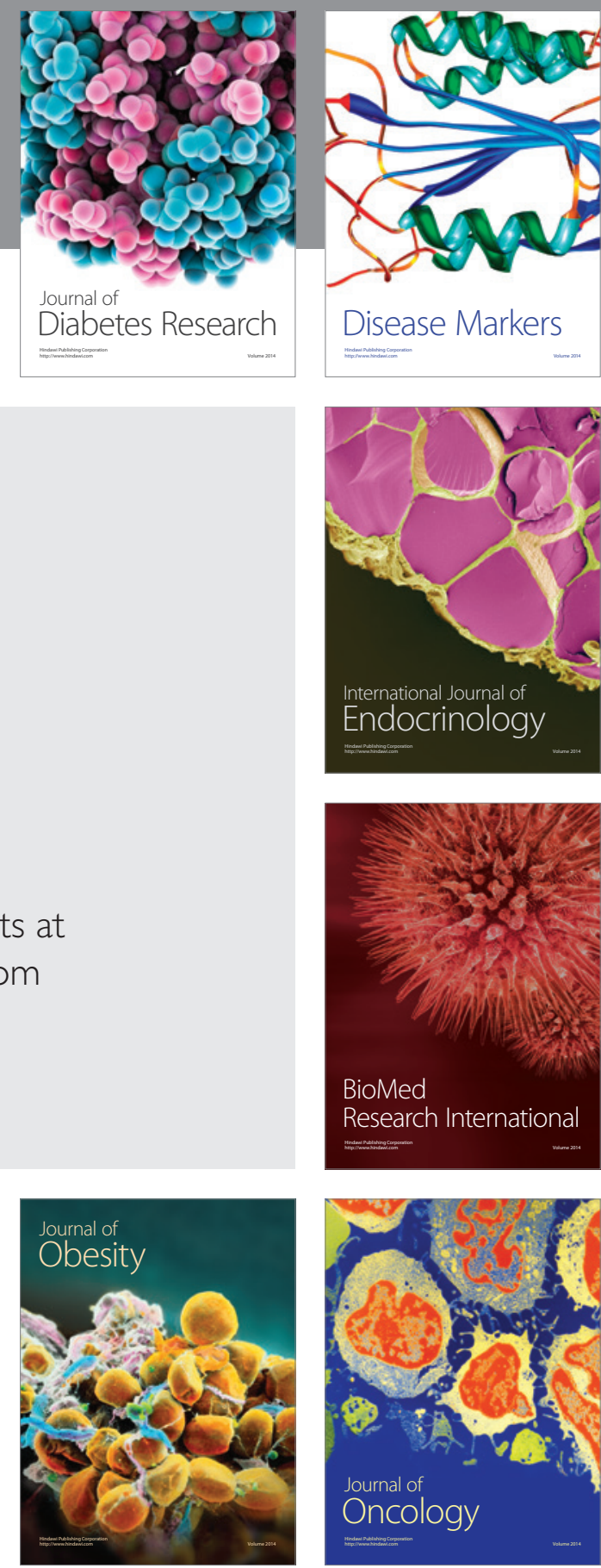

Disease Markers
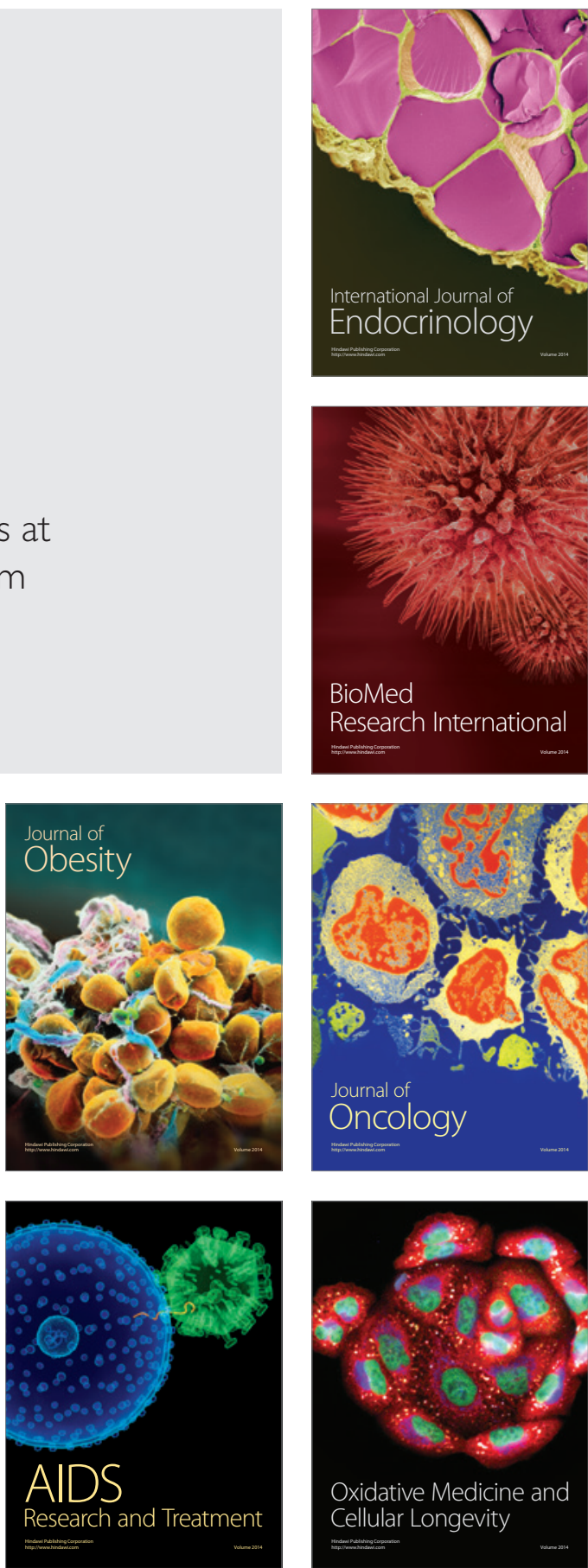